\title{
Management of children with prolonged diarrhea [version 1;
}

\section{peer review: 3 approved]}

\author{
Antonietta Giannattasio, Alfredo Guarino (D), Andrea Lo Vecchio
}

Department of Translational Medical Sciences - Section of Pediatrics, University of Naples, Federico II, Via S. Pansini 5, Naples, 80131, Italy

V1 First published: 23 Feb 2016, 5(F1000 Faculty Rev):206

https://doi.org/10.12688/f1000research.7469.1

Latest published: 23 Feb 2016, 5(F1000 Faculty Rev):206

https://doi.org/10.12688/f1000research.7469.1

\section{Abstract}

Prolonged diarrhea is usually defined as acute-onset diarrhea lasting 7 days or more, but less than 14 days. Its trend has been declining in recent years because of improvement in the management of acute diarrhea, which represents the ideal strategy to prevent prolonged diarrhea. The pathogenesis of prolonged diarrhea is multifactorial and essentially based on persistent mucosal damage due to specific infections or sequential infections with different pathogens, hostrelated factors including micronutrient and/or vitamin deficiency, undernutrition and immunodeficiency, high mucosal permeability due to previous infectious processes and nutrient deficiency with consequential malabsorption, and microbiota disruption. Infections seem to play a major role in causing prolonged diarrhea in both developing and developed areas. However, single etiologic pathogens have not been identified, and the pattern of agents varies according to settings, host risk factors, and previous use of antibiotics and other drugs. The management of prolonged diarrhea is complex. Because of the wide etiologic spectrum, diagnostic algorithms should take into consideration the age of the patient, clinical and epidemiological factors, and the nutritional status and should always include a search for enteric pathogens. Often, expensive laboratory evaluations are of little benefit in guiding therapy, and an empirical approach may be effective in the majority of cases. The presence or absence of weight loss is crucial for driving the initial management of prolonged diarrhea. If there is no weight loss, generally there is no need for further evaluation. If weight loss is present, empiric anti-infectious therapy or elimination diet may be considered once specific etiologies have been excluded.

\section{Keywords}

Prolonged Diarrhea, Persistent Diarrhea, Children, Malnutrition

\section{Open Peer Review}

Approval Status
version 1
23 Feb 2016
Faculty Reviews are review articles written by the

prestigious Members of Faculty Opinions. The articles are commissioned and peer reviewed before publication to ensure that the final, published version is comprehensive and accessible. The reviewers who approved the final version are listed with their names and affiliations.

1. Sean Moore, Cincinnati Children's Hospital Medical Center, Cincinnati, USA

2. Hans Hoekstra, Hieronymus Bosch Hospital, Hertogenbosch, The Netherlands

3. Jorge Amil Dias, Hospital S. João, Porto, Portugal

Any comments on the article can be found at the end of the article. 
Corresponding author: Alfredo Guarino (alfguari@unina.it)

Competing interests: No competing interests were disclosed.

Grant information: The author(s) declared that no grants were involved in supporting this work.

Copyright: $\odot 2016$ Giannattasio A et al. This is an open access article distributed under the terms of the Creative Commons Attribution License, which permits unrestricted use, distribution, and reproduction in any medium, provided the original work is properly cited.

How to cite this article: Giannattasio A, Guarino A and Lo Vecchio A. Management of children with prolonged diarrhea [version 1; peer review: 3 approved] F1000Research 2016, 5(F1000 Faculty Rev):206 https://doi.org/10.12688/f1000research.7469.1

First published: 23 Feb 2016, 5(F1000 Faculty Rev):206 https://doi.org/10.12688/f1000research.7469.1 


\section{Introduction and context}

Diarrheal disorders are a major health problem in pediatrics worldwide. Accounting for more than 750,000 deaths in children under the age of 5 per year, they are the second leading cause of death in this population according to the World Health Organization $(\mathrm{WHO})^{1}$. Definitions of diarrheal episodes are usually based on the duration of symptoms rather than etiology. However, there is little consistency and agreement on the definition of acute, prolonged, persistent, and chronic diarrhea in pediatric and adult subjects and in developed and developing countries. In a systematic review on 138 trials, Johnston et al. identified 64 different definitions of diarrhea and 69 definitions of diarrhea resolution. The definitions provided by the WHO were the most commonly used (Table 1$)^{2}$.

Most diarrheal illnesses last 5-7 days and are due to self-limiting intestinal infections. These episodes are usually defined as acute diarrhea (AD). According to WHO, episodes of diarrhea are usually classified as $\mathrm{AD}$ when they last up to a maximum of 14 days and "persistent or chronic diarrhea" when they last $>14$ days ${ }^{3}$. However, a subset of children experiences an acute-onset diarrhea lasting 7 days or more, but less than 14 days; this may be defined as prolonged diarrhea (ProD) and usually indicates an episode that continues beyond the expected duration of a typical acute infectious diarrhea ${ }^{4}$. This entity accounts for a relatively small but consistent number of diarrheal episodes that, especially in developing countries, is associated with a high risk of mortality and morbidity ${ }^{4}$. In this review, we define ProD as an episode of diarrhea of acute onset lasting 7 to 13 days and persistent diarrhea (PD) as diarrhea lasting 14 or more days.

\section{Epidemiology and risk factors}

Data on the etiology and epidemiology of ProD are limited because of the huge variability in defining diarrheal disorders. Some evidence may be extrapolated from studies reporting data on $\mathrm{PD}^{5-7}$.

In a study in Israeli children, about a quarter of the study population presented with ProD (lasting 8-13 days) and 14-18\% with PD (14 or more days' duration $)^{6}$. However, Moore et al. firstly proposed the definition of ProD as a specific disorder and reported an incidence of $12 \%$ of all diarrheal cases in a large Brazilian cohort, accounting for a quarter of all days of diarrhea recorded in the 10 -year study period ${ }^{4}$. In the same population, less than $5 \%$ presented with PD. It should be noted that when a diarrheal episode progresses from acute to ProD, there is a 6-fold higher risk that the episode will evolve into $\mathrm{PD}^{4}$.

ProD is more common in children aged 6 to 24 months and peaks in the second semester of life ${ }^{4}$. Children who developed ProD in their first year of life have a doubled risk of developing PD at pre-school age ${ }^{4}$. In addition, children experiencing severe diarrhea

Table 1. Definitions of diarrheal illnesses.

Diarrhea

Acute diarrhea

Prolonged diarrhea

Persistent diarrhea

Post-infectious diarrhea

Intractable diarrhea

Congenital diarrhea
The most commonly recognized definition of diarrhea is based on World Health Organization parameters and define diarrhea by the passage of 3 or looser than normal stools in the preceding 24-hour period. An episode of diarrhea is defined as lasting 1 day or more and usually ends after at least 2 days without diarrhea.

Episode of self-limiting diarrhea with acute onset, typically lasting 5 to 7 days. In most cases, it is due to an intestinal infection and may be combined to fever and vomiting, meeting the definition of acute gastroenteritis. Acute diarrhea may be also related to extra-intestinal infections (i.e. urinary infection, viral respiratory infections), food-poisoning, iatrogenic intestinal damage (i.e. chemotherapy, radiotherapy) or other intestinal and extra-intestinal diseases such as acute appendicitis.

Acute onset diarrhea lasting from 7 to 14 days not covering the definition of persistent diarrhea. It is usually due to persistent infections or to post-infectious intestinal damage (i.e. carbohydrate malabsorption, small intestine bacterial overgrowth) that may prolong the duration of diarrhea behind the expected time. Some experts refer to this as acute-protracted diarrhea.

Diarrhea lasting 14 days or more, usually associated with weight loss, ultimately leading to severe nutritional impairment and that may require clinical nutrition.

The classical definition of persistent diarrhea was intended to exclude some causes of chronic diarrhea such as celiac disease or inflammatory bowel diseases.

In many contexts chronic diarrhea is a synonymous of persistent diarrhea. The World Health Organization uses this definition rather than persistent diarrhea.

However, chronic diarrhea usually does not have an acute onset and is the manifestation of structural and inflammatory bowel disorders.

Some experts refer to chronic diarrhea in case of episodes lasting more than 4 weeks.

Acute onset diarrhea lasting 7 to 14 days and following an episode of acute gastroenteritis. This definition is covered by prolonged diarrhea.

Non-infectious diarrhea lasting more than 14 days, intractable despite extensive hospital therapy. Typical of young infants, usually below 3 months (but not only). Typically needs intravenous fluids or clinical nutrition and is related to high mortality.

Congenital diarrhea is an inherited enteropathy with a typical onset early in life. For many of these conditions, severe chronic diarrhea represents the main clinical manifestation, while in others, diarrhea is only a component of a more complex multi-organ or systemic disease. 
Table 2. Etiology of Prolonged Diarrhea in children. HIV: human immunodeficiency virus.

\begin{tabular}{|l|}
\hline Infections \\
\hline Viruses \\
\hline Rotavirus \\
Norovirus \\
Sapovirus \\
Astrovirus \\
Cytomegalovirus (HIV-infected children) \\
\hline Bacteria \\
\hline Shigella \\
Enteroaggregative E. coli (EAgg EC) \\
Enteropathogenic E. coli (EPEC) \\
Clostridium difficile \\
Campylobacter \\
Yersinia \\
Mycobacterium avium complex (HIV-infected children) \\
\hline Parasites \\
\hline Cryptosporidium \\
Giardia lamblia \\
Cyclospora \\
Entamoeba histolytica \\
\hline Small Intestine Bacterial Overgrowth - SIBO \\
\hline Underlying malnutrition \\
\hline Vitamins and Micronutrients deficiency (Zinc, Vitamin A) \\
\hline Food-induced diarrhea \\
\hline Lactose intolerance \\
Carbohydrate malabsorption \\
Cow-milk protein intolerance \\
Ceod allergy \\
\hline Antibiotic-associated diarrhea \\
\hline
\end{tabular}

and dysenteric illnesses with blood and mucus in their stools are more likely to present with a course longer than those who present with mild-to-moderate diseases ${ }^{8,9}$.

These findings, that demonstrate a close relationship between ProD and PD, may be due to different mechanisms: on one hand, ProD affects child growth and mucosal immunity and impacts on gut microflora and intestinal barrier functions; on the other hand, the increased risk of subsequent episodes may be related to specific individual features or to genetic, nutritional, or environmental characteristics that predispose to persistent intestinal illnesses. Mainly in developing areas, ProD is linked with malnutrition in a complex cause-effect relationship, implicating a multifactorial "vicious cycle" involving intestinal infections, microflora disruption, micronutrient deficiency, and immunodeficiency. The role of malnutrition is supported by the evidence that non-breast-fed children and those who are weaned early or recently exposed to formula, as well as children with underlying malnutrition, vitamin deficiency, and wasting, are at increased risk of developing $\operatorname{ProD}^{4,8-10}$.
Environmental factors also contribute to ProD, since living in poor areas with poor hygiene conditions and low mothers' education expose children to a doubled risk of developing ProD ${ }^{4}$.

Finally, the risk of ProD is reduced by half for 10 years' increase in maternal age, and if a mother completes primary school, the risk of ProD and PD in her child decreases ${ }^{6}$.

Irrespective of the etiology and risk factors, children with ProD have a higher risk of nutritional derangement, micronutrient deficiency, risk of developing PD, infections, and immunodeficiency.

\section{Etiology and pathophysiology}

The pathogenesis of ProD is multifactorial and essentially based on 1) persistent mucosal damage due to specific agents or sequential infections with different pathogens, 2) host-related factors including micronutrient and/or vitamin deficiency, undernutrition, and immunodeficiency, 3) high mucosal permeability due to previous infectious processes and nutrient deficiency with consequent malabsorption, and 4) microbiota disruption (Figure 1). In some cases, ProD may represent the onset of chronic intestinal disorders including celiac disease, inflammatory bowel disease (IBD), and autoimmune enteropathies that are usually characterized by PD.

In children with PD, electron microscopy shows shortening of villi, decrease in number and height of microvilli, blunting of borders of enterocytes, loss of glycocalyx, and presence of mucous pseudomembranes coating the epithelial surface. In addition, children with PD often have marked mucosal inflammation when compared to children with $\mathrm{AD}$, presenting higher interferon-gamma response, significant elevation of fecal lactoferrin, interleukin (IL)-8, and IL-1 $\beta$, and a higher percentage of $\mathrm{CD}^{+} \mathrm{T}$ cells ${ }^{11-13}$. More than half of children with severe AD or ProD develop protein-losing enteropathy ${ }^{14}$. Also, children with ProD share some of these immunological characteristics.

\section{Microbial agents}

Although infections are a major cause of ProD, there is no clear evidence of a role for selected pathogens in inducing $\operatorname{ProD}^{6,8,14}$.

In developing countries, many of the bacterial pathogens responsible for AD and dysentery also cause PD. Invasive diarrhea due to Shigella contributes to ProD and PD, and the prevalence of Shigella among children with ProD and PD is higher than in those with $\mathrm{AD}^{6,8,15-17}$. Enteropathogenic Escherichia coli have been found in at least $25 \%$ of children tested in low- and middle-income countries and may cause ProD in some settings ${ }^{5,7,8}$.

Selected viruses may be responsible for ProD. Rotavirus, norovirus, and sapovirus have been found in as many as $50 \%$ of diarrheal episodes resolving within the third week in children living in the United States ${ }^{18}$. In some cases, such as rotavirus infection, ProD could be due to susceptibility to other infections or to nutrient malabsorption rather than being the direct result of the pathogenic agent ${ }^{11}$. About $10 \%$ of astrovirus infections may complicate $\mathrm{AD}$ with prolonged episodes of diarrhea, even in non-immunocompromised patients ${ }^{19}$. 


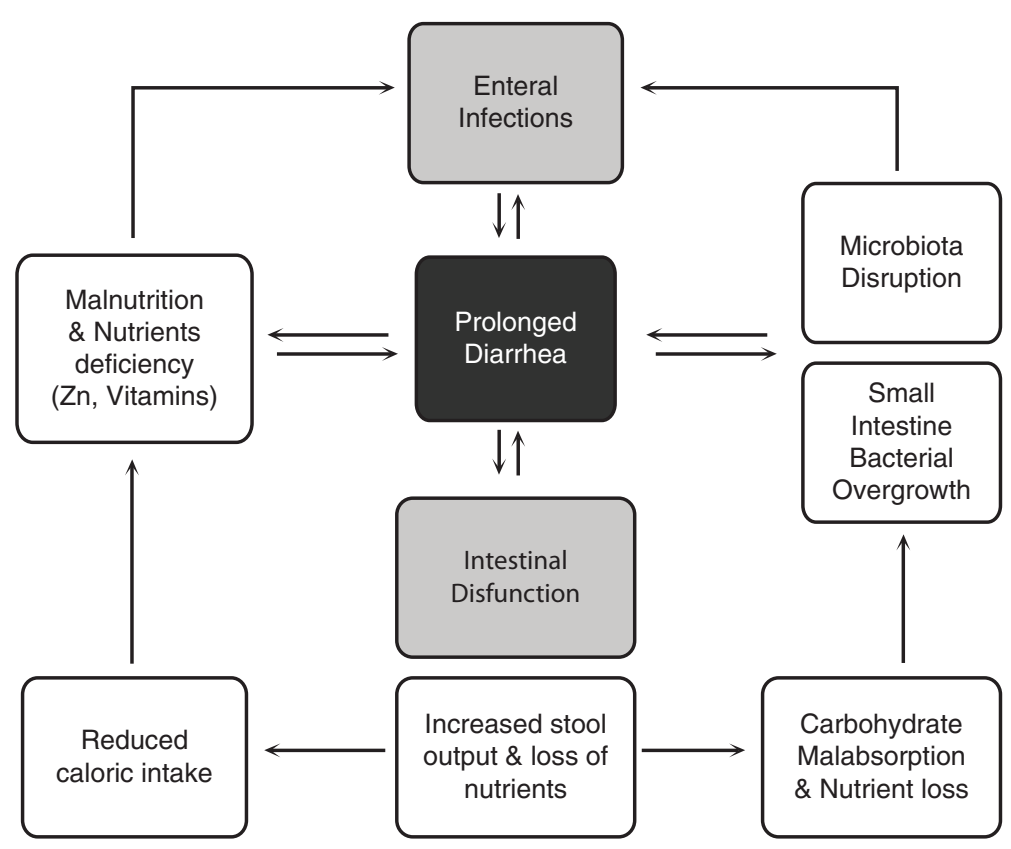

Figure 1. Multifactorial etiology of prolonged diarrhea. "Vicious cycle" of prolonged diarrhea involves intestinal infections, microflora disruption, micronutrient deficit, undernutrition, and immunodeficiency.

Parasites including Giardia, Cryptosporidium, and Cyclospora have been related to ProD and PD in developing areas. Cryptosporidium, a common agent of ProD and PD in HIV-infected children, was frequently isolated also in immunocompetent children ${ }^{4}$.

Although $35-70 \%$ of children with PD tested positive for at least one pathogen, multiple isolations are common, making it difficult to distinguish bystanders from agents causing illness ${ }^{5,6}$.

In addition, the pattern of microorganisms that tends to be associated with ProD is different in developed and developing countries. In the former, viruses are more frequently found, whereas in developing countries, specific bacteria and protozoa are more common.

\section{Small intestinal bacterial overgrowth}

A further mechanism that may cause ProD is so-called small intestinal bacterial overgrowth (SIBO). It involves the colonization of the small intestine by bacteria that are usually found in the colonic microbiota or an increase in their number. SIBO is more common in children with underlying intestinal diseases, such as blind loop syndrome, dysmotility, or inflammatory diseases of the intestine. However, SIBO may be a possible complication of AD due to recent infection, the presence in the intestinal lumen of carbohydrates and short-chain fatty acids, the temporary alteration of gut motility, or previous antimicrobial use. It has been associated with antacid therapy. The bacterial overgrowth in the small intestine causes inflammation and malabsorption of liposoluble vitamins and steatorrhea with further worsening of diarrhea and malnutrition.

\section{Malnutrition and malabsorption}

ProD and PD are commonly seen in association with malnutrition and micronutrient deficiencies in developing areas. The latter conditions cause the impairment of immunological mechanisms for clearing infections as well as delayed intestinal repair, thereby contributing to the vicious cycle between diarrhea and malnutrition ${ }^{20}$.

PD is also due to malabsorption of select nutrients. Food intolerance and food allergy may be responsible for ProD. The mucosal damage secondary to infection leads to loss of lactase activities with a consequent malabsorption of carbohydrates that, due to their osmotic power, worsen and perpetuate diarrhea.

In addition, the increased permeability related to both acute infection and underlying malnutrition may potentially lead to food-antigen sensitization.

\section{Post-infectious irritable bowel syndrome}

Some children and adolescents may develop functional gastrointestinal symptoms, including PD, following a single infectious episode of diarrhea. The clinical picture is characterized by diarrhea and abdominal pain without loss of body weight. This is a syndrome defined as chronic non-specific diarrhea of childhood or "toddler's diarrhea" and is currently named post-infectious irritable bowel syndrome. The Rome III criteria define the type of symptoms and their duration in age groups ${ }^{21}$. Based on age-related criteria, the diagnosis can be made without further investigation.

\section{Diagnostic approach}

The management of ProD is complex because the etiology and pathogenesis are complex. Furthermore, the majority of available data on management and treatment are focused on PD rather than on ProD and very few studies have examined ProD as a distinct category ${ }^{4}$. 
In developing countries, the main consequences of ProD are nutritional derangement, morbidity (with an increased risk of hospital admission), and even death ${ }^{14}$. In this setting, it is difficult to perform expensive and time-consuming tests to identify the etiology of ProD. Optimal management of AD is the ideal strategy to prevent ProD. It includes appropriate fluid replacement, zinc treatment, and optimal nutrition in developing countries ${ }^{22}$. Rotavirus vaccination, promotion of breast-feeding, promotion of hand washing, improved water supply and quality, and community-wide sanitation indirectly prevent ProD ${ }^{23,24}$. However, the diagnostic approach to and the treatment of ProD is a challenge. Because of the wide etiologic spectrum, diagnostic algorithms of ProD should also include the age of the patient, clinical and epidemiological factors, and the results of microbiological investigations, when available. An algorithm for ProD is provided in Figure 2. The algorithm is intended as a general tool, and decisions must take into consideration medical history and clinical features of individual cases as described below.

\section{Clinical evaluation}

Specific clues in the family and personal history (previous episodes of $\mathrm{AD}$ or ProD, history of chronic diseases or food allergy, and immunological status) may provide useful indications.

Initial clinical examination should include the evaluation of general and nutritional status and the presence of weight loss. Dehydration requires prompt supportive interventions to stabilize the child. Malnutrition may precede the onset of diarrhea, contributing to its duration, or it could be the consequence of the disease. The presence or absence of weight loss may help drive the subsequent diagnostic and therapeutic approach (Figure 2).

Some children may lose weight as a consequence of poor caloric input after an episode of $\mathrm{AD}$, and in these cases, reintroduction of a free diet is generally effective. However, most children with ProD and weight loss deserve specific medical interventions and careful follow up. If first-line therapeutic interventions do not result in a clear clinical improvement and diarrhea persists, a referral to the gastroenterologist is needed (Figure 2).

If there is no evidence of weight loss, in most cases there is no need for further investigation. However, a clinical re-evaluation with assessment of the trend of symptoms and weight and revision of nutritional regimens may be considered. Children with persistence of symptoms may need to be referred to the gastroenterologist for further care.

\section{Laboratory and other investigations}

The initial diagnostic workup for children with ProD should include stool cultures and a search for parasites and enteric viruses. However, the wide pattern of microorganisms potentially involved requires high-level techniques.

Although traditional culture is still an invaluable tool in clinical settings, in some instances other techniques are needed for the identification and differentiation of bacterial species ${ }^{25}$. For other pathogens, it is more important to identify the toxins than the organisms themselves, as in the case of enterotoxigenic E. coli, Shiga toxin of enterohemorrhagic E. coli, and Clostridium difficile $e^{26}$.
Light microscopy represents the traditional technique used to diagnose intestinal parasites. However, its sensitivity depends on the burden of infection, the stage and delivery to the labs of the specimen, and the experience of the observer ${ }^{26}$. More sensitive and specific enzyme-linked immunosorbent assay (ELISA) and polymerase chain reaction (PCR) analysis are used to detect protozoa in fecal samples, but these assays are still not routinely available.

Enteric viruses are commonly searched for by means of ELISA and latex agglutination analysis. However, molecular genetic techniques detect a wider spectrum of pathogens than conventional techniques and provide information about their molecular epidemiology ${ }^{25}$. Again, these techniques are not readily available in primary care settings and in resource-limited areas.

A search for SIBO should also be included in the diagnostic work-up of ProD. Breath hydrogen test may identify an abnormal bacterial proliferation in the small bowel; it can also be used to detect carbohydrate malabsorption ${ }^{27}$. However, the sensitivity and specificity of this test is low and it is difficult to perform, mainly in young children. Alternatively, a simple measurement of stool $\mathrm{pH}$ or a test for reducing substances (Clinitest) may be easily done at the bedside to investigate carbohydrate (usually lactose) malabsorption. Other specific diagnostic tests, including evaluation of intestinal function and inflammation, imaging, and endoscopy, should be performed in case of persistence of diarrhea in the setting of pediatric gastroenterology.

Non-invasive diagnostic tests for intestinal and pancreatic function (including dual absorption test, xylosemia, iron oral load, lipase, and fecal elastase) and inflammation (fecal calprotectin and last ileal loop abdominal ultrasound) may provide useful information for diagnosis, when available ${ }^{27,28}$. Although abdominal ultrasound may be affected by subjective evaluation if an expert consultant is available, it may be of support in management. The association of a negative scan of last ileal loop with negative fecal calprotectin significantly reduces the possibility of $\mathrm{IBD}^{28}$. The use of noninvasive diagnostic tests in the diagnostic algorithm may reduce invasive procedures. However, if diagnosis is not obtained otherwise, endoscopy with biopsy should be considered.

In young children with a familial history of atopy and suggestive personal history and clinical features, skin tests for the screening of food allergy (including patch tests and prick tests) may be performed and elimination diet with subsequent challenge should be considered $^{29}$.

\section{Treatment}

\section{Empiric treatment}

Expensive laboratory evaluations usually are of little benefit in guiding the successful treatment of ProD, and an empirical therapeutic approach may be effective in the majority of cases (Figure 2).

If there is no weight loss, the approach should be conservative and no investigations are generally needed. A review of the diet is worthwhile, including a check on a possible excess of sugar-containing drinks as a cause of diarrhea. Feeding pattern should be normalized according to the " $4 \mathrm{~F}$ " rule: fat (increase dietary lipids to at least 


\section{Prolonged diarrhea (> 7 days)}

Clinical assessment

Patient and family anamnesis for:

Dietary history, Infections/allergies/intestinal diseases

Growth charts

Weight monitoring

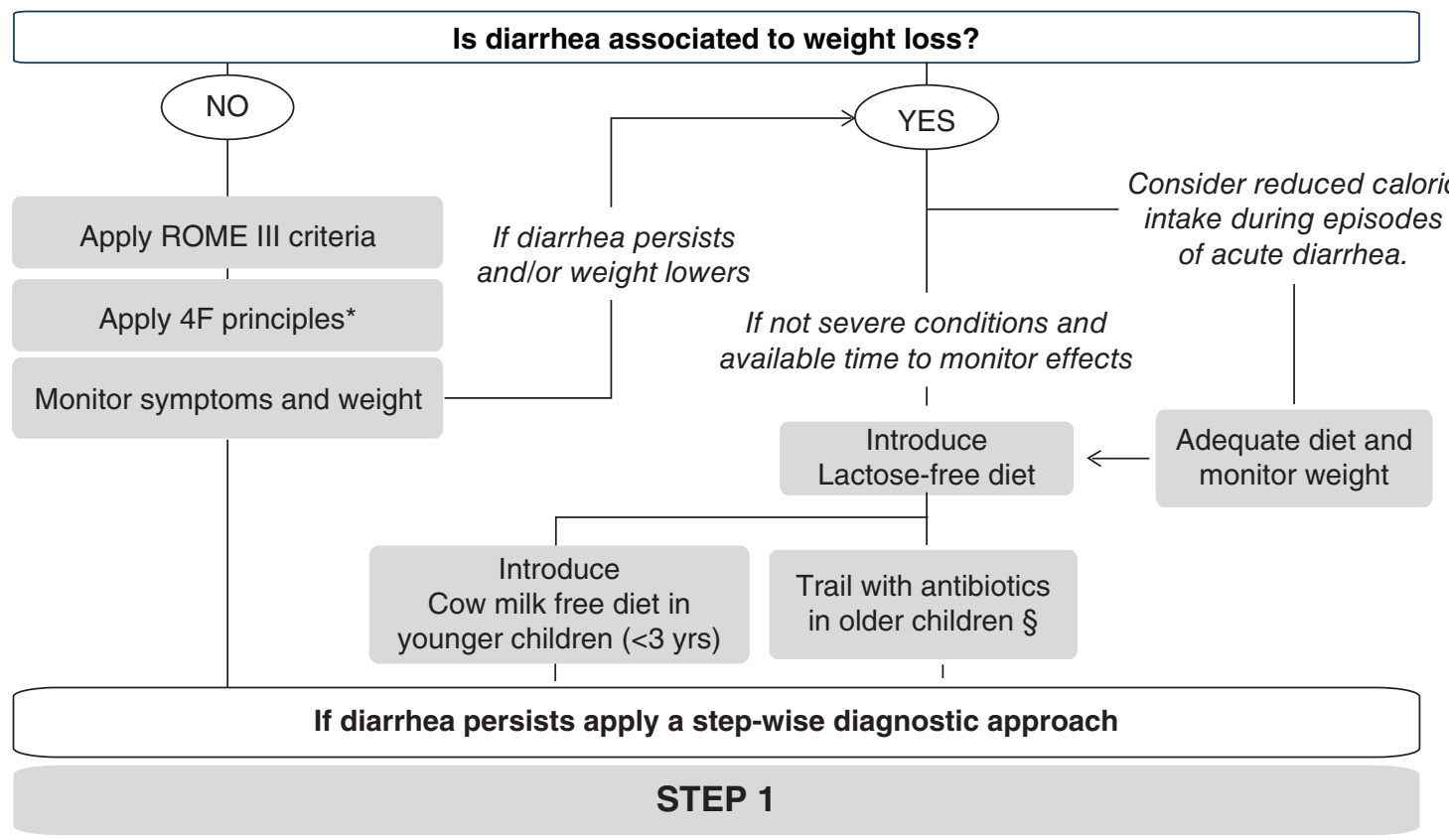

Microbiology (stool cultures, microscopy for parasites, viruses, $\mathrm{H}_{2}$-breath test)

Screening test for celiac disease

Tests for food allergy (patch/prick tests)/food challenge according to family and personal history Non invasive tests for:

- intestinal function (including double sugar test, xylosemia, iron absorption test)

- pancreatic function (amylase, lipase, fecal elastase)

- intestinal inflammation (fecal calprotectin, rectal nitric oxide)

Abdominal Ultrasounds (scan of last ileal loop)

\section{Following steps should be performed in Reference Center for Pediatric Gastrointestinal Diseases}

(Endoscopy and standard jejunal/colonic histology, electron microscopy, special investigations as intestinal immunohistochemistry, anti-enterocyte antibodies, serum chromogranin and catecholamines, brush border enzymatic activities, motility and electrophysiological studies

Figure 2. Diagnostic and therapeutic approach to prolonged diarrhea. *Feeding pattern should be normalized according to the "4F" role: fat (increase dietary lipids to at least 35-40\% of total daily energy intake), fiber (normalize fiber intake by introduction of fruits and wholegrain bread), fluid (restrict fluid intake if history is significant for high fluid consumption), and fruit juice (discourage overconsumption of fruit juices, especially those containing sorbitol or a high fructose/glucose ratio). $\S$ Empiric antibiotic treatment should cover most probable enteric infections (Shigella and enteropathogenic Escherichia coli) and/or small intestine bacterial overgrowth. 
$35-40 \%$ of total daily energy intake), fiber (normalize fiber intake by introduction of fruits and wholegrain bread), fluid (restrict fluid intake if history is significant for high fluid consumption), and fruit juice (discourage overconsumption of fruit juices, especially those containing sorbitol or with a high fructose/glucose ratio).

A lactose-free diet can be started if weight loss is present. Some children with ProD who do not have weight loss at first presentation may benefit from a lactose-free diet since disaccharidase deficiency secondary to AD is relatively common. Exclusion diets are usually administered with the double purpose of overcoming food intolerance, which may be the primary cause of ProD, or its complication. The sequence of elimination should be graded from less (e.g. cow's milk protein hydrolysate) to more restricted diets (amino acid-based formula) according to the child's clinical conditions. This approach should be reserved for infants and young children.

\section{Antimicrobials}

ProD is often an infection-induced illness in the majority of cases ${ }^{30}$. However, considering that pathogens associated with ProD are also often found in healthy children without diarrhea ${ }^{7}$, even when an enteric pathogen is detected, it is not always clear that this is the cause of the illness.

Antimicrobial agents are indicated for the treatment of selected parasites $^{31}$ and selected enteropathogenic bacteria, such as enteropathogenic E. coli and enteroaggregative E. coli ${ }^{14}$. Pathogens such as Shigella and Cryptosporidium are commonly associated with ProD in tropical, developing countries and should be treated in case of ProD ${ }^{4}$.

Nitazoxanide is a broad-spectrum antimicrobial agent with activity against protozoa, nematodes, cestodes, trematodes, and bacteria, with a favorable safety profile ${ }^{32,33}$. It is effective in childhood cryptosporidiosis $^{34}$ but not consistently in undernourished children or in HIV-infected patients ${ }^{35}$. Anecdotal cases of children successfully treated with nitazoxanide because of PD ( $<30$ days) have been reported ${ }^{36}$. This strategy seems to be effective in select situations, saving time-consuming tests to identify the cause of diarrhea ${ }^{36}$.

Metronidazole can be used for Giardia, and trimethoprimsulfamethoxazole can be used for Cyclospora and as a second-line antibacterial drug for a number of pathogens ${ }^{14}$.

Very few data on the treatment of viral ProD are available. Human immunoglobulin, available for intravenous use, may be administered orally (300 mg/kg of body weight) in a single dose. The rationale of passive immunotherapy is based on the demonstration of neutralizing antibodies against all viruses in a medical preparation of immunoglobulins ${ }^{37}$. They are found in the stools after administration, and this treatment reduces the duration of stay in severe and/or immunocompromised patients with $\mathrm{AD}$ and in patients with severe diarrheal episodes due to rotavirus ${ }^{38,39}$. This treatment seems to also have a potential role in immunocompromised patients with norovirus enteritis ${ }^{40}$. In this population, a positive trend towards resolution of diarrhea and decreased stool output in the treatment group compared with placebo was found, but no benefit was reported for length of hospital stay or hospital $\cos ^{40}$. However, no data on oral immunoglobulins and viral-ProD is available, with the exception of rotavirus ${ }^{41}$.

Ciprofloxacin is effective in cases of diarrhea associated with enteroaggregative $E$. coli in HIV-infected adults ${ }^{42}$. However, its efficacy needs to be proven in a large-scale trial in children with ProD.

The efficacy of antimicrobials in children with ProD in whom etiology is unknown is even more controversial. In a recent systematic review in young children with PD of unknown or non-specific cause from developing countries, no difference was demonstrated for oral gentamicin or metronidazole compared with placebo, whereas sulfamethoxazole-trimethoprim was more effective than placebo for diarrhea at 7 days and for total stool volume ${ }^{43}$. To date, the evidence to recommend the use of antibiotics in ProD of unknown or non-specific causes is still limited.

\section{Probiotics}

Some data support the use of probiotics in ProD. Lactobacillus spp. and Saccharomyces boulardii significantly reduced the number of stools and duration of diarrhea in children with PD ${ }^{44}$.

A recent Cochrane review showed that probiotics shortened the duration of diarrhea and reduced stool frequency and hospital stay. However, only four trials with a small number of participants were available for meta-analysis. The authors concluded that, although probiotics appear to hold promise as adjunctive therapy, there is insufficient evidence to recommend their routine use in children with ProD ${ }^{45}$.

\section{Nutritional interventions}

Dietary treatment is crucial in ProD. However, nutritional interventions are often expensive and poorly applicable in developing countries. Locally available, inexpensive foods and vitamin and mineral supplementation have been proposed ${ }^{46-48}$. Locally tailored nutritional interventions are ideal in the developing world: they are inexpensive and culturally acceptable, provide sufficient levels of energy and nutrients to malnourished children, and allow the continuation of dietary therapy at home ${ }^{46,49}$.

A multicenter study in severely ill children aged 4-36 months with PD showed a high success rate of a dietary regimen using inexpensive, locally available foods (variable association of rice, maize, lentils, chicken, yoghurt, milk, sucrose or glucose, and oil) and vitamin and mineral supplementation ${ }^{46}$. Although a recent systematic review underlined the low-quality evidence of these studies, the authors found no evidence to support the use of proprietary formulas or specialized ingredients over the use of locally produced and readily available foods in the treatment of either $\mathrm{AD}$ or $\mathrm{PD}^{50}$.

Other approaches that have been evaluated include the use of amylase-rich flours in cereal-based porridges to decrease viscosity and thus increase nutrient density and children's nutrient intake. However, these trials have been performed only in children with $\mathrm{AD}^{51}$. Also, mixed diets including specific ingredients thought or known to have antidiarrheal properties, such as green banana, have been tested. These reports showed a significantly higher cumulative probability of recovery in children ${ }^{52,53}$. 
Children with ProD and malnutrition may present with deficiency of selected micronutrients such as vitamin A, zinc, folic acid, copper, and selenium ${ }^{54}$. Zinc was found to have therapeutic efficacy (typically resolution of small bowel damage and shortening duration of diarrhea) in several trials of $\mathrm{PD}^{55}$. Zinc and vitamin $\mathrm{A}$ in combination seem to be even more effective than either vitamin A or zinc alone in reducing PD in developing countries ${ }^{56}$.

\section{Conclusion}

In children with severe malnutrition, ProD may be the direct result of secondary immunodeficiency and the consequence of a reduction of intestinal absorptive-digestive surface. In this condition, nutritional interventions (nutritional regimen review/optimization and micronutrient supplementation) should be considered with the aim of optimizing the use of residual functioning intestine over time. Enteral nutrition given continuously by feeding tube may be used in severe cases of reduction of intestinal functional surface. However, anti-infectious therapy should also be considered.

Overall, the treatment of ProD is a balance between a possible infectious etiology and a nutritional approach. When, however, the features of irritable bowel syndrome (defined according to the Rome III criteria) are met, no specific medication should be prescribed. However, parental reassurance and diet tailoring (e.g. an increase in fiber intake) may be helpful, and counseling/behavioral therapy may be indicated to reduce anxiety that may trigger gastrointestinal symptoms. If a specific cause of diarrhea is detected, such as celiac disease or IBD, an appropriate therapy should be started.

\section{Abbreviations}

WHO, World Health Organization; AD, acute diarrhea; ProD, prolonged diarrhea; $\mathrm{PD}$, persistent diarrhea; IBD, inflammatory bowel disease; SIBO, small intestinal bacterial overgrowth.

\section{Author contributions}

AGi, AG, and ALV devised the paper. AGi and ALV carried out the systematic literature research. AGi and ALV prepared the first draft. AG provided substantial contribution to the preparation of the manuscript. ALV and AGi prepared figures and tables. All authors were involved in the revision of the draft manuscript and have agreed to the final content.

\section{Competing interests}

No competing interests were disclosed.

\section{Grant information}

The author(s) declared that no grants were involved in supporting this work.
1. World Health Organization: Diarrhoeal disease. 2013. Reference Source

2. Johnston BC, Shamseer L, da Costa BR, et al:: Measurement issues in trials of pediatric acute diarrheal diseases: a systematic review. Pediatrics. 2010; 126(1): e222-31.

PubMed Abstract | Publisher Full Text

3. World Health Organization: Persistent diarrhoea in children in developing countries: memorandum from a WHO meeting. Bull World Health Organ. 1988; 66(6): 709-17.

PubMed Abstract | Free Full Text

4. F Moore SR, Lima NL, Soares AM, et al.: Prolonged episodes of acute diarrhea reduce growth and increase risk of persistent diarrhea in children. Gastroenterology. 2010; 139(4): 1156-64.

PubMed Abstract | Publisher Full Text | Free Full Text | F1000 Recommendation

5. Abba K, Sinfield R, Hart CA, et al.: Pathogens associated with persistent diarrhoea in children in low and middle income countries: systematic review. BMC Infect Dis. 2009; 9: 88.

PubMed Abstract | Publisher Full Text | Free Full Text

6. Fraser D, Dagan R, Porat N, et al.: Persistent diarrhea in a cohort of Israel Bedouin infants: role of enteric pathogens and family and environmental factors. J Infect Dis. 1998; 178(4): 1081-8. PubMed Abstract | Publisher Full Text

7. Lima AA, Moore SR, Barboza MS Jr, et al: Persistent diarrhea signals a critical period of increased diarrhea burdens and nutritional shortfalls: a prospective cohort study among children in northeastern Brazil. J Infect Dis. 2000; 181(5): 1643-51.

PubMed Abstract | Publisher Full Text

8. F Das SK, Faruque AS, Chisti MJ, et al:: Changing trend of persisten diarrhoea in young children over two decades: observations from a larg diarrhoeal disease hospital in Bangladesh. Acta Paediatr. 2012; 101(10): e452-7.

PubMed Abstract | Publisher Full Text | F1000 Recommendation
9. Lima AA, Guerrant RL: Persistent diarrhea in children: epidemiology, risk factors, pathophysiology, nutritional impact, and management. Epidemiol Rev 1992; 14: 222-42.

PubMed Abstract

10. Mathai J, Raju B, Bavdekar A, et al.: Chronic and persistent diarrhea in infants and young children: status statement. Indian Pediatr. 2011; 48(1): 37-42. PubMed Abstract | Publisher Full Text

11. Azim T, Ahmad SM, Sefat-E-Khuda, et al.: Immune response of children who develop persistent diarrhea following rotavirus infection. Clin Diagn Lab Immunol. 1999; 6(5): 690-5. PubMed Abstract | Free Full Text

12. Taniguchi K, Rikimaru T, Yartey JE, et al.: Immunological background in children with persistent diarrhea in Ghana. Pediatr Int. 1999; 41(2): 162-7. PubMed Abstract | Publisher Full Text

13. Steiner TS, Lima AA, Nataro JP, et al:: Enteroaggregative Escherichia coli produce intestinal inflammation and growth impairment and cause interleukin- 8 release from intestinal epithelial cells. J Infect Dis. 1998; 177(1): 88-96. release from intestinal epithelial cells.
PubMed Abstract | Publisher Full Text

14. Ochoa TJ, Salazar-Lindo E, Cleary TG: Management of children with infectionassociated persistent diarrhea. Semin Pediatr Infect Dis. 2004; 15(4): 229-36. PubMed Abstract | Publisher Full Text

15. Baqui $A H$, Black RE, Sack RB, et al:: Epidemiological and clinical characteristics of acute and persistent diarrhoea in rural Bangladeshi children. Acta Paediatr Suppl. 1992; 381(Supplement s383): 15-21. PubMed Abstract | Publisher Full Text

16. Mahalanabis D, Alam AN, Rahman N, et al.: Prognostic indicators and risk factors for increased duration of acute diarrhoea and for persistent diarrhoea in children. Int J Epidemiol. 1991; 20(4): 1064-72. PubMed Abstract | Publisher Full Text

17. F Ahmed F, Ansaruzzaman M, Haque E, et al.: Epidemiology of postshigellosis persistent diarrhea in young children. Pediatr Infect Dis J. 2001; 20(5): 525-30. PubMed Abstract | Publisher Full Text | F1000 Recommendation 
18. F Vernacchio L, Vezina RM, Mitchell AA, et al.: Characteristics of persisten diarrhea in a community-based cohort of young US children. $J$ Pediatr Gastroenterol Nutr. 2006; 43(1): 52-8.

PubMed Abstract | Publisher Full Text | F1000 Recommendation

19. Caballero S, Guix S, El-Senousy WM, et al:: Persistent gastroenteritis in children infected with astrovirus: association with serotype-3 strains. J Med Virol. 2003 71(2): 245-50.

PubMed Abstract | Publisher Full Tex

20. Bhutta ZA: Post-infectious persistent diarrhea in developing countries. Textbook of Pediatric Gastroenterology and Nutrition. Editor: Stefano Guandalini. Taylor \& Francis. 2004; 193-200. Reference Source

21. Rasquin A, Di Lorenzo C, Forbes D, et al.: Childhood functional gastrointestinal disorders: child/adolescent. Gastroenterology. 2006; 130(5): 1527-37. PubMed Abstract | Publisher Full Text

22. Dickinson B, Surawicz CM: Infectious diarrhea: an overview. Curr Gastroenterol Rep. 2014; 16(8): 399.

PubMed Abstract | Publisher Full Tex

23. UNICEF/WHO: Diarrhoea: why children are still dying and what can be done. Geneva: WHO Press, 2009; 1-68. Reference Source

24. Guarino A, Winter $\mathrm{H}$, Sandhu B, et al: Acute gastroenteritis disease: Report of the FISPGHAN Working Group. J Pediatr Gastroenterol Nutr. 2012; 55(5): 621-6. PubMed Abstract | Publisher Full Text

25. Guarino A, Giannattasio A: New molecular approaches in the diagnosis of acute diarrhea: advantages for clinicians and researchers. Curr Opin Gastroenterol. 2011; 27(1): 24-9.

PubMed Abstract | Publisher Full Text

26. Pawlowski SW, Warren CA, Guerrant R: Diagnosis and treatment of acute or persistent diarrhea. Gastroenterology. 2009; 136(6): 1874-86. PubMed Abstract | Publisher Full Text | Free Full Text

27. Guarino A, De Marco G: Persistent diarrhea. In RE Kleinman, IR Sanderson, O Goulet, PM Sherman, G Mieli-Vergani, \& BL Shneider (Eds.), Walker's pediatric gastrointestinal disease: Pathology, diagnosis, management. ISBN 978-1-55009364-3. 5th ed., 2008; 265-274.

28. Canani RB, de Horatio LT, Terrin G, et al.: Combined use of noninvasive tests is useful in the initial diagnostic approach to a child with suspected inflammatory bowel disease. J Pediatr Gastroenterol Nutr. 2006; 42(1): 9-15. PubMed Abstract | Publisher Full Text

29. F Koletzko S, Niggemann B, Arato A, et al.: Diagnostic approach and management of cow's-milk protein allergy in infants and children: ESPGHAN GI Committee practical guidelines. J Pediatr Gastroenterol Nutr. 2012; 55(2): 221-9.

PubMed Abstract | Publisher Full Text | F1000 Recommendation

30. Nataro JP, Sears CL: Infectious causes of persistent diarrhea. Pediatr Infect Dis J. 2001; 20(2): 195-6. PubMed Abstract

31. Farthing MJ: Diarrhoea: a significant worldwide problem. Int J Antimicrob Agents. 2000; 14(1): 65-9.

PubMed Abstract | Publisher FullText

32. F Diaz E, Mondragon J, Ramirez E, et al:: Epidemiology and control of ntestinal parasites with nitazoxanide in children in Mexico. Am J Trop Med Hyg. 2003; 68(4): 384-5.

PubMed Abstract | F1000 Recommendation

33. White AC Jr: Nitazoxanide: an important advance in anti-parasitic therapy. Am J Trop Med Hyg. 2003; 68(4): 382-3.

PubMed Abstract

34. F Rossignol JF, Ayoub A, Ayers MS: Treatment of diarrhea caused by Cryptosporidium parvum: a prospective randomized, double-blind, placebo-controlled study of Nitazoxanide. J Infect Dis. 2001; 184(1): 103-6. PubMed Abstract | Publisher Full Text | F1000 Recommendation

35. Sears CL, Kirkpatrick BD: Is nitazoxanide an effective treatment for patients with acquired immune deficiency syndrome-related cryptosporidiosis? Nat Clin Pract Gastroenterol Hepatol. 2007; 4(3): 136-7. PubMed Abstract | Publisher Full Text

36. F Cohen SA: Use of nitazoxanide as a new therapeutic option for persisten diarrhea: a pediatric perspective. Curr Med Res Opin. 2005; 21(7): 999-1004. PubMed Abstract | Publisher Full Text | F1000 Recommendation

37. Guarino A, Canani RB, Russo S, et al:: Oral immunoglobulins for treatment of acute rotaviral gastroenteritis. Pediatrics. 1994; 93(1): 12-6. PubMed Abstract | Publisher Full Text

38. Guarino A, Ashkenazi S, Gendrel D, et al.: European Society for Pediatric Gastroenterology, Hepatology, and Nutrition/European Society for Pediatric Infectious Diseases evidence-based quidelines for the management of acute gastroenteritis in children in Europe: update 2014. J Pediatr Gastroenterol Nutr. 2014; 59(1): 132-52.

PubMed Abstract | Publisher Full Tex

39. Guarino A, Albano F, Canani RB, et al.: HIV, fatal rotavirus infection, and treatment options. Lancet. 2002; 359(9300): 74

PubMed Abstract | Publisher Full Text

40. Florescu DF, Hermsen ED, Kwon JY, et al: Is there a role for oral human immunoglobulin in the treatment for norovirus enteritis in immunocompromised patients? Pediatr Transplant. 2011; 15(7): 718-21. PubMed Abstract | Publisher Full Text

41. Guarino A, Guandalini S, Albano F, et al:: Enteral immunoglobulins for treatment of protracted rotaviral diarrhea. Pediatr Infect Dis J. 1991; 10(8): 612-4. PubMed Abstract | Publisher Full Text

42. Wanke CA, Gerrior J, Blais V, et al:: Successful treatment of diarrheal disease associated with enteroaggregative Escherichia coli in adults infected with human immunodeficiency virus. J Infect Dis. 1998; 178(5): 1369-72. PubMed Abstract | Publisher Full Text

43. F Abba K, Sinfield R, Hart CA, et al:: Antimicrobial drugs for persistent diarrhoea of unknown or non-specific cause in children under six in low and middle income countries: systematic review of randomized controlled trials. BMC Infect Dis. 2009; 9: 24.

PubMed Abstract | Publisher Full Text | Free Full Text | F1000 Recommendation

44. F Gaón D, García H, Winter L, et al.: Effect of Lactobacillus strains and Saccharomyces boulardii on persistent diarrhea in children. Medicina (B Aires). 2003; 63(4): 293-8.

PubMed Abstract | F1000 Recommendation

45. F Bernaola Aponte G, Bada Mancilla CA, Carreazo NY, et al:: Probiotics for treating persistent diarrhoea in children. Cochrane Database Syst Rev. 2013; 8 CD007401

PubMed Abstract | Publisher Full Text | F1000 Recommendation

46. F Evaluation of an algorithm for the treatment of persistent diarrhoea: a multicentre study. International Working Group on Persistent Diarrhoea. Bull World Health Organ. 1996; 74(5): 479-89. PubMed Abstract | Free Full Text | F1000 Recommendation

47. de Mattos AP, Ribeiro TC, Mendes PS, et al:: Comparison of yogurt, soybean, casein, and amino acid-based diets in children with persistent diarrhea. Nutr Res. 2009; 29(7): 462-9.

PubMed Abstract | Publisher Full Tex

48. Valentiner-Branth P, Steinsland H, Santos G, et al:: Community-based controlled trial of dietary management of children with persistent diarrhea: sustained beneficial effect on ponderal and linear growth. Am J Clin Nutr. 2001; 73(5): 968-74.

PubMed Abstract

49. Brown $\mathrm{KH}$ : Appropriate diets for the rehabilitation of malnourished children in the community setting. Acta Paediatr Scand Suppl. 1991; 374(Supplement s374): $151-9$.

PubMed Abstract | Publisher Full Text

50. F Gaffey MF, Wazny K, Bassani DG, et al.: Dietary management of childhood diarrhea in low- and middle-income countries: a systematic review. $B M C$ Public Health. 2013; 13(Suppl 3): S17.

PubMed Abstract | Free Full Text | F1000 Recommendation

51. Mitra AK, Rahman MM, Mahalanabis D, et al: Evaluation of an energy-dense meal liquefied with amylase of germinated wheat in children with acute watery diarrhoea: a randomized controlled clinical trial. Nutr Res. 1995; 15(7): 939-51. Publisher Full Text

52. F Rabbani GH, Larson CP, Islam R, et al.: Green banana-supplemented diet in the home management of acute and prolonged diarrhoea in children: a community-based trial in rural Bangladesh. Trop Med Int Health. 2010; 15(10): $1132-9$.

PubMed Abstract | Publisher Full Text | F1000 Recommendation

53. F Rabbani GH, Teka T, Zaman B, et al.: Clinical studies in persistent diarrhea: dietary management with green banana or pectin in Bangladeshi children. Gastroenterology. 2001; 121(3): 554-60. PubMed Abstract | Publisher Full Text | F1000 Recommendation

54. Bhan MK, Bhandari N, Bahl R: Management of the severely malnourished child: perspective from developing countries. BMJ. 2003; 326(7381): 146-51. PubMed Abstract | Publisher Full Text | Free Full Text

55. F Black RE: Zinc deficiency, infectious disease and mortality in the developing world. $J$ Nutr. 2003; 133(5 Suppl 1): 1485S-9S. PubMed Abstract | F1000 Recommendation

56. F Rahman MM, Vermund SH, Wahed MA, et al:: Simultaneous zinc and vitamin A supplementation in Bangladeshi children: randomised double blind controlled trial. BMJ. 2001; 323(7308): 314-8.

PubMed Abstract | Publisher Full Text | Free Full Text | F1000 Recommendation 


\section{Open Peer Review}

\section{Current Peer Review Status:}

\section{Editorial Note on the Review Process}

Faculty Reviews are review articles written by the prestigious Members of Faculty Opinions. The articles are commissioned and peer reviewed before publication to ensure that the final, published version is comprehensive and accessible. The reviewers who approved the final version are listed with their names and affiliations.

\section{The reviewers who approved this article are:}

\section{Version 1}

\section{Jorge Amil Dias}

Unit of Paediatric Gastroenterology, Hospital S. João, Porto, Portugal

Competing Interests: No competing interests were disclosed.

\section{Hans Hoekstra}

Department of Pediatrics,, Hieronymus Bosch Hospital, Hertogenbosch, The Netherlands

Competing Interests: No competing interests were disclosed.

\section{Sean Moore}

Cincinnati Children's Hospital Medical Center, Cincinnati, OH, USA

Competing Interests: No competing interests were disclosed.

The benefits of publishing with F1000Research:

- Your article is published within days, with no editorial bias

- You can publish traditional articles, null/negative results, case reports, data notes and more

- The peer review process is transparent and collaborative

- Your article is indexed in PubMed after passing peer review

- Dedicated customer support at every stage

For pre-submission enquiries, contact research@f1000.com 